\title{
Smart technology: tools to bridge the skill-gap and bring in new workers
}

\begin{abstract}
The need for trained or trainable individuals to fill the expanding open jobs in manufacturing has never been greater. Recently the number of available positions has been generally larger than the number of people looking for work-this is the very first time to ever happen since the Department of Labor (DOL) began tracking job turnover more than twenty years ago. This number (according to the DOL) shows that roughly 7.6 million jobs are available to a workforce of 6.5 million active job seekers. Unless measures are implemented soon this problem will only increase and will create a drag on the manufacturing environment. This paper will address potential solutions that could be employed to assist lower skilled along with unskilled workers a method to enter the skilled workforce-by use of smart tools.
\end{abstract}

Volume 3 Issue 4 - 2019

\author{
Michael E Johnson \\ Department of Aeronautics/Aviation, Capital Technology \\ University, USA
}

\begin{abstract}
Correspondence: Michael E Johnson, Department of Aeronautics/Aviation, Capital Technology University, Maryland, USA, Tel 470-439-4109, Email mejohnson@captechu.edu
\end{abstract}

Received:September 18, 2019 | Published: October 15, 2019

Keywords: artificial intelligence, aviation, manufacturing, education, skills

Abbreviations: DOL, department of labor; CTE, career and technical education; VR, virtual reality; AR, augmented reality; GPS, global position systems; XR, extended reality

\section{Introduction}

Education has always been the cornerstone of the industrialized nation. The strength and opportunity afforded has made it possible to create the middle class and to take many people from modest beginnings to staggering achievements. Yet, it seems that in recent years the prevailing belief among many is that without a college degree you will not be successful. There seems to be a lack of focus as to what degrees are truly helpful and what this is seen in the demands of the manufacturing labor force. According to Bill Koenig, ${ }^{1}$ a Senior Editor with manufacturing.org, in a survey conducted in 2018 indicated a lack of skills and "impending retirements" of current workers suggest the industry could experience employment shortfalls, to the level of 2.4 million positions going unfilled by 2028 . This shortfall translates into $\$ 454$ billion in production risk and loss. ${ }^{1}$

In 1992 BMW announced that the company was interested in establishing an automotive manufacturing plant in Spartanburg, South Carolina. This area boasts a population of 334,600 and a gross metro product of 15.6 billion. The average income is $\$ 48,765$ with only $24.1 \%$ of the population having a College degree. With this population pool, BMW looked to staff an operation and manufacturing site with an initial need for 1000 workers. ${ }^{2}$ BMW pulled from a population of relatively under skilled workers and using team leads and focused development, trained individuals for specific work function such as welding: a procedure that has recently been filled by automation. BMW came into the area with the understanding that they would keep costs down to company by forgoing the introduction of automation systems that require highly skilled workers to operate and or maintain. With the use of a smaller focused skill group, the company was able to establish a presence in an area that had not been known for high skill. While this worked in the early 1990's the increase in need has pushed to more and more reliance on high tech solutions. ${ }^{3}$ Currently, the BWM operations center has a workforce of 8,800 employees and has established themselves in the community and surrounding areas as an innovator and that of a company that was willing to go the extra mile for the worker.

For the sake of clarity, let's define what makes a skilled worker in comparison to that of the unskilled. The definition of unskilled is that of "someone who does not process specialized or skilled training in some area". This can be exhibited by an individual with a high school diploma and no other training. Lacking any other specialized training or knowledge, this has historically been the largest area of growth in the United States labor pool. Though in recent years, jobs that had not required any specialized training have been vanishing due to technological advancements and societal changes. The jobs that once required little to no training or those that could be taught during application now require some form of formal training. For Instance, with the introduction of computers in the manufacturing process and now being used on the manufacturing floor it is apparent that the old ideas of the apprentice worker must be updated to be inline with today's needs.

\section{Education concerns}

The educational pipeline that has historically feed the needs of industry in the United States has seen a disturbing trend in the focus of archived degrees. For instance, in 2014 to 2015 there were 1,895,000 bachelor's degrees conferred, the greatest numbers of degrees were conferred in the fields of business $(364,000)$, health professions and related programs $(216,000)$, social sciences and history $(167,000)$, psychology $(118,000)$, biological and biomedical sciences $(110,000)$, engineering $(98,000)$, visual and performing arts $(96,000)$, and education $(92,000)$. At the master's degree level, the greatest numbers of degrees were conferred in the fields of business $(185,000)$, education $(147,000)$, and health professions and related programs $(103,000)$. At the doctor's degree level, the greatest numbers of degrees were conferred in the fields of health professions and related programs $(71,000)$, legal professions and studies $(40,300)$, education $(11,800)$, engineering $(10,200)$, biological and biomedical sciences $(8,100)$, psychology $(6,600)$, and physical sciences and science technologies $(5,800)$. 
In recent years, the numbers of bachelor's degrees conferred have followed patterns that differed significantly by field of study. While the number of bachelor's degrees conferred increased by 32 percent overall between 2004-05 and 2014-15, there was substantial variation among the different fields of study, as well as shifts in the patterns of change during this time. For example, the number of degrees conferred in computer and information sciences decreased 27 percent between $2004-05$ and 2009-10, but then increased 50 percent between 2009-10 and 2014-15. In contrast, the number of bachelor's degrees conferred in the combined fields of engineering and engineering technologies increased 12 percent between 200405 and 2009-10, and then increased a further 30 percent between 2009-10 and 2014-15. In several other major fields, the number of bachelor's degrees also increased by higher percentages in the second half of the 10-year period than in the first half.

Degreed workers cannot fill the needed slots that are waiting. The need for technical or trade school training is desperately needed to fill the gaps. Unfortunately, due to expense (which can preclude many from attending traditional college) there are gaps in the available teachers with expertise in many technical fields. One touted reason for this is the prevalent low pay as in comparison to working in the technical field or that fewer people are focusing on technical secondary training. According to an article published from PBS in 2017 "career and technical education (CTE) are in shortage for at least $2 / 3$ of the states in the US". 5

Compounding the reduced activity in individuals seeking STEM (Science, Technology, Engineering and Math) focused degrees are that of the retirement of the baby boomers. The baby boomers (people born between the early to mid-1940s to 1964) represent about $20 \%$ of the American public ${ }^{6}$ this generation of people represents a disproportionate pool of the technical/skilled workforce. As these workers retire from the labor pool, they take with them enormous skills that the market can little afford to lose. This becomes a perfect storm of attrition to the work force-lack of trained individuals, retirement of a skilled work force and the explosion of need. One of the unfortunate side effects of labor shortages is that the time to train and re-populate the pool can take years and with experienced workers retiring the resupply of experience is in question (Figure 1).

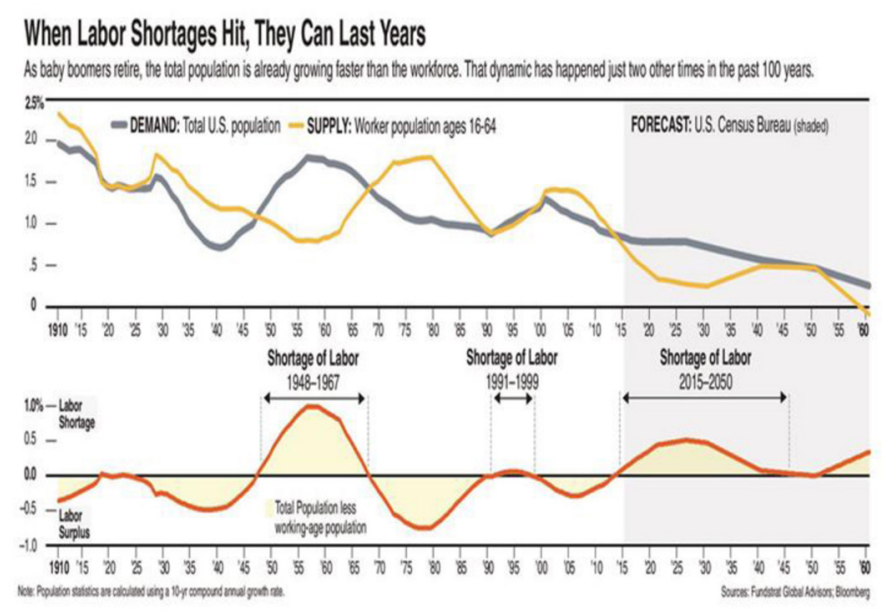

Figure I Source: Barron's Magazine Online. ${ }^{7}$

The graph above shows how from the early 20th century to today the areas where there has been a deep need for labor and a lack of able and skilled workers to fill triggers a slump. The events that trigger the decline range from periods of political and economic instability, but the result are that the slumps can last for years. These periods can exacerbate situations that make it difficult to recover from.

One area of stopgap measure is the use of the H1B visa. ${ }^{8}$ To attract the best and brightest to American companies, the United States Government uses a visa directed not at immigration but employment on a fixed period. The H1B is an American visa aimed at skilled (generally graduate level) workers in specialty areas that demand experience and training in theoretical or technical focus in fields such as Information Technology, finance, accounting, engineering, mathematics, science or medicine and the like. ${ }^{6}$ If you do not have a Bachelor or Master degrees you may be afforded the opportunity to show the degree equivalence via work experience or training. The H1B only allows the worker to stay in the United States for no more than 6 years and while easier to obtain that that of a green card (immigration status) there is a cap or limit on the number of people allowed to even petition. This cap is set 65,000 according to the statistics and information site for the United States immigration page. 65,0000 workers on a limited time cannot maintain nor can it truly stem the tide and need for today's and the tomorrow's work force. It is imperative that we reach the pool that seems to have the greatest number of workers available-but with the biggest drawbackunskilled labor in a skilled work environment.

\section{Technology as a bridge}

For the first time in the industrial age, we have achieved technological advancements that can level the skill gaps. We can use tools that had found in the realms of science fiction yesterday, today. For example, the use of virtual reality (VR) (Figure 2).

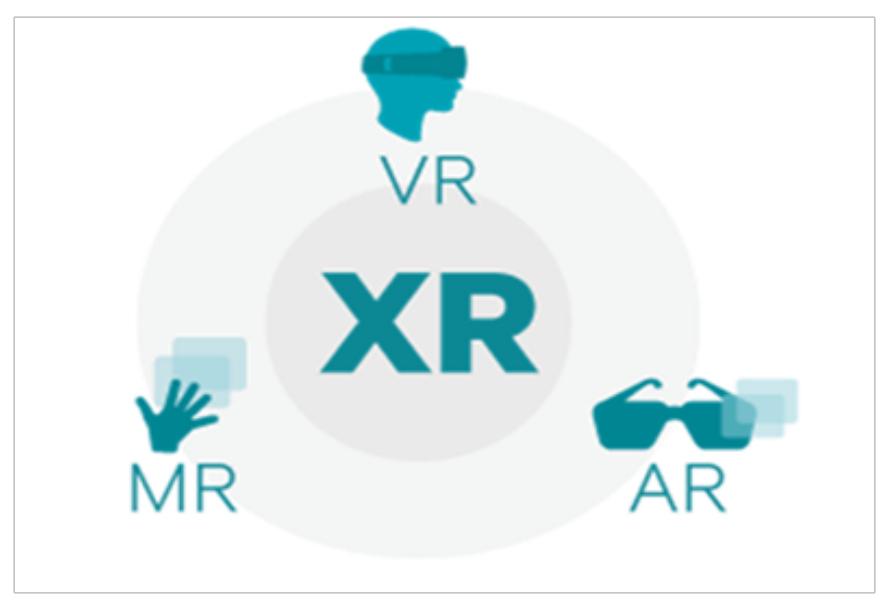

Figure 2 Components of extended reality, Source: medium.com

The world of extended reality can be subdivided into 3 primary areas. These being VR or virtual reality. This immersive experience is also known computed simulated environment or reality. With the use of a headset and headphones, the user is brought into an imaginary world filled with visual, auditory and other sensations. Considered well established and mature from its use in the gaming world VR is being repurposed into more practical applications Augmented Reality (AR) is a live and direct or indirect view of the physical environment where the elements are augmented or supplemented by a computergenerated input like sound, video, graphics or location service such as GPS (Global Position Systems). When you consider how AR is superimposed over the real environment, it offers a greater freedom 
than that of the VR closed environment. Currently AR is popular with mobile or tablet devices-but its here that the bridge for skills could be built.

Before delving into the AR proposal, it is necessary to look at the other components found in XR. Mixed Reality or MR is a hybrid reality that is the merging or real and virtual environments to produce a hybrid reality. The crux of MR is that the computer delivered content and the real-world portions can react to each other in real time. Extended Reality (XR) is a relatively new term used to encompass other aspects of computer delivered realities. It refers to all real and virtual combined environments and human to machine interfaces using computer technology or that of a wearable device such as the Hololens by Microsoft or that of the Google Glass attachment (Figure 3). To sum up-VR is a completely immersive environment where the individual is presented with a virtual reality. AR is an overlay of virtual elements and cannot interact with real environment. MR is that of a mixture of virtual and real elements that interact with one another and XR is the umbrella that encompasses the entire technology.

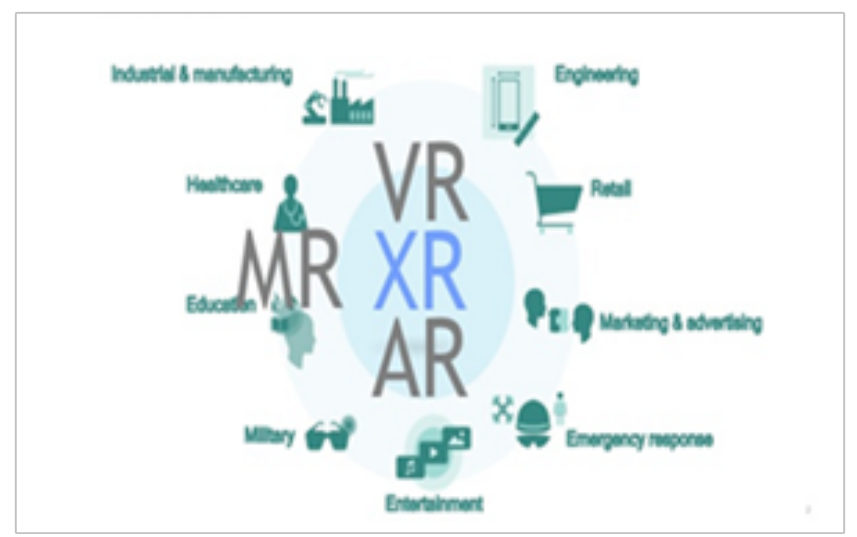

Figure 3 XR/AR uses currently, Source: medium.com

\section{Bringing virtual into reality}

During the last recession recorded as December 2007 to June $2009^{9}$ the United States lost about 3.2 percent of the work force. These losses were mostly found in the populous called unskilled labor. In the study"Education Participation, and the revival of U.S. Economic Growth" (9) Dale W. Jorgenson of Harvard University, et.al write "The growth rate of the U.S. economy in the next decade will depend critically on the revival of the labor force participation rates that prevailed before the Great Recession," they write that group with the most room for growth is non-degreed workers. ${ }^{10}$

The real question is how we most efficiently and quickly integrate this vast resource into the United States economic engine. While the use of Community College and targeted vocational education is one avenue, I want to visit the use of specialized tools and systems such as augmented reality or AR. Augmented reality is the use of a handheld or wearable technology that superimposes images within the realworld view of the user. Here is a tool that could be utilized to help create one of the needed bridges for all workers. Consider if you will the nature of wearable technology, namely that of glasses (Figure 4).

Google Glass was initial launched in 2013 to the public as the next personal computer experience. At a considerable price point of $\$ 1500.00$ USD these were deemed as nothing more than a very expensive toy. Fast forward 6 years and the toy of yesterday can assist workers with the projects of today. Google Glass in its original iteration offered the ability to browse the internet, take photographs and or videos and give direction. While the product was less than enthusiastically embraced by an apathetic public, it has remained in the background. In the recent years, there has been a drive to see where tools such as the Google Glass and others could assist in the work environment. Take for instance manufacturing and a repetitive process or action.

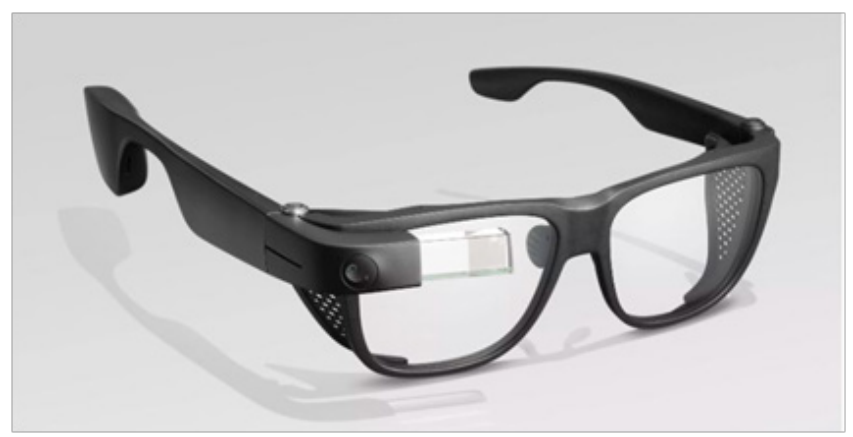

Figure 4 Google glass prototype, Source: cnet website news

In 2016, Boeing Aircraft decided to test the idea if there may be a better way to build and deploy the wire harness and bundles that are built for their aircraft. The electrical systems in aircraft are immensely complex and by nature messy in deployment. Historically the process involves the use of a PDF printout or displayed on the computer screen which requires the technician to move between a diagram and the wire bundle or plug that is being worked on the chance of error is truly proportional to the complexity of the operation. Some of the plugs or connection ends can require more than 100 individual connections. Boeing put out a proposal looking for a company that could assist them and one responded. Working with Upskill, the developers of a smart glass platform called Skylight, Boeing was able to integrate a system that cut production time by $25 \%$ and lowered rework to nearly zero. ${ }^{11}$ Skylight via the google glass tool is a system that allowed the user to scan a QR code, which pulls the wireless harness software, and then scan another code to load the assembly instructions. The app supports Glass voice commands, and lets users stream what they are seeing to another technician in the event of something unexpected (Figure 5).

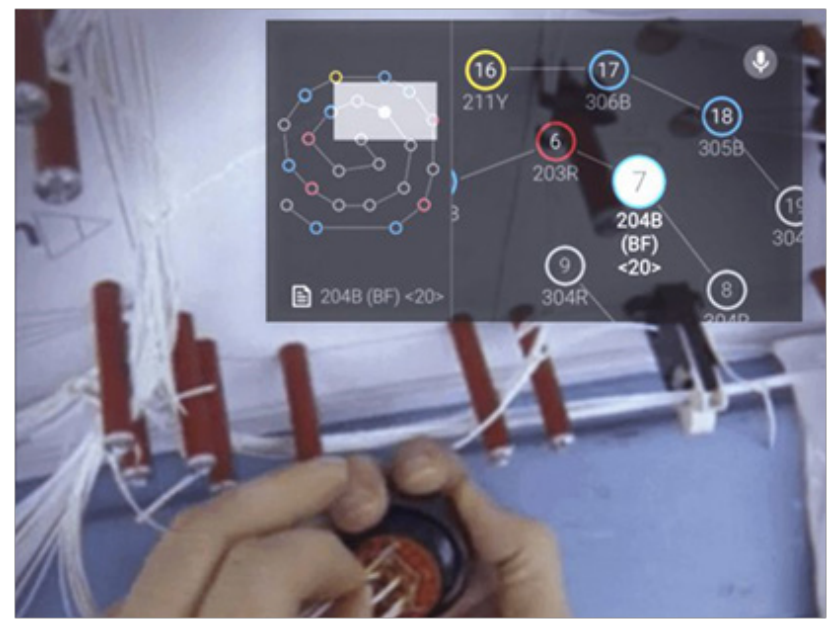

Figure 5 Using skylight ${ }^{\mathrm{TM}}$ via google glass, Source: Upskill and Boeing use skylight 
Utilizing these types of tools and having a technician (skilled or trained) act as oversight, it would be possible to teach unskilled workers in the application of skilled tasks. For instance, using visual prompts as displayed below, a specialized task could be taught in the work environment. This is only one area where this could be applied. The initial testing phase of the Boeing APX project has been completed and at the time of this writing is currently in use in areas around the company. However, there is so much more that can be done. There are numerous solutions to the problems the work force is facing, unfortunately these solutions can and are cost prohibitive, not immediate in remedy (there is a maturation period needed in retraining) and there will be a needed 'belt tightening' by industry and political leadership. We need a deep and total commitment to the education of our country along with sweeping overhaul of the college or vocational track. It is imperative that we start now and with minimal delay we are only inviting the unavoidable disaster our inaction will bring. The largest growing segment of the working population is that of unskilled labor. As this paper has shown we have, for the $1 \mathrm{st}$ time, the ability to utilize technology that will bring parity to skilled -unskilled labor force and will (if utilized to its full extent) an explosion in manufacturing and building potential we need but seize the initiative and as the United States has many times-Lead the Way.

\section{Summary}

This paper discussed an apparent trend in labor needs and availability. This trend indicates that the largest growing segment in the work force is that of unskilled labor. With the use of current and anticipated technology, we could usher in a largely under skilled segment into high skilled areas. This would require minor adjustments to current thinking. If we do not, we could stagnate the manufacturing potential of the country for a long period. This paper has been hyper focused on the use of a narrow set of technology and doesn't consider the importance and need for community colleges and the technical college. These both have a huge impact and are vital to the improvement of the worker but were not the subject of this paper. This paper was to show a small section outside of what is considered a standard path - namely the use of technology and its impact today.

\section{Acknowledgments}

None.

\section{Conflicts of interest}

Author declares that there is no conflict of interest.

\section{References}

1. William K. Upto $2.4 m$ manufacturing jobs may go unfilled by 2028 , study says. Advanced manufacturing; 2018.

2. Metropolitan statistical information: Spartanburg. Forbes business review.

3. Levin DP. What BMW sees in South Carolina? Newyork Times; 1993.

4. Unskilled labor definition.

5. Gonser S. With our shortage of skilled workers career and technical education is ready to be taken seriously. PBS; 2018.

6. Digest of education statistics, 2016 (NCES 2017-094). Chapter 3. U.S. department of education, national center for education statistics; 2018.

7. Lee T. The great labor crunch. Barron's Online; 2018.

8. H-1B Specialty Occupations, DOD Cooperative Research and Development Project Workers, and Fashion Models; 2019.

9. BLS spotlight on statistics: the recession of 2007-2009. BLS; 2012.

10. Dale JW, Ho MS, Samuels JD. Education, participation, and the revival of the U.S. economic growth. The National Bureau of Economic Research; 2016.

11. Upskill Video Promo. Upskill and Boeing Use Skylight to Reinvent Wire Harness Assembly. Youtube.com; 2017. 